climate in which any scientific development came about, its antecedents and its influence.

In a book of about two hundred and fifty pages the author cannot hope to give anything like an adequate treatment to the fifty-one topics which he selects. The work is a good bedside book, but it is difficult to divine why the author did not try to make it more systematic. It is hopeful to see the 'discovery' of radioactivity immediately following and connected with the account of the 'discovery' of X-rays-a sequence of events which is often forgotten, but it is difficult to know why the 'discovery' of argon has been placed between the "Concept that Neutrinos must exist" and the "Synthesis Element of 101"; and the 'discovery" of safety glass between the 'discovery' of helium and Mendel's Laws of heredity.

In the fifty-one 'discoveries', atomic physics comes off best of all, chemical synthesis and engineering a bad second and biology scarcely runs at all. The first twentyfive chapters are intended for the layman, and include Haber's interesting speculation that, but for the 'discovery' of the fixation of nitrogen a few years before the First World War (the author in error prints after), the War would have terminated soon after the battle of the Falkland Islands and the whole course of European history since 1916 would have been different. The author certainly flatters the British layman by expecting him to grasp without explanation the meaning of terms and words used to describe Carothers's work in nylon synthesis. What will the layman make of this, for example, ". . . the Superpolymer from hexamethylenediamine and adipic acid was first synthesized. The resulting polymer, polyhexamethyleneadipamide, was called 66 "? Of course, if the author has failed to achieve adequate communication to the non-specialist, he has failed, in a goodly company, to achieve the well-nigh impossible. Section 2 of the book, which for the most part deals with atomic physics, is intended "for the scientists and the layman". Each chapter has a set of references to original papers appended. The quality of the production of the book is good. Errors are few: an occasional date is wrong and Kekulé's Traumerei is misspelt; and one may ask, if the Americans write 'sulfur', why do they still retain 'naphtha' ?

The author dips into many things and certainly should stimulate the imagination of the open-minded reader, but what is now wanted is a better distribution of the topics between the various branches of science and a further analysis of each on the lines of the Harvard Case Books. This could only be achieved in a very much larger volume or volumos.

W. L. SUMNER

\section{THE COMPUTER'S BRADSHAW}

An Index of Mathematical Tables

By Dr. A. Fletcher, Dr. J. C. P. Miller, Dr. L. Rosenhead and Dr. L. J. Comrie. Second edition. Vol. 1: Introduction. Part 1: Index According to Functions. Pp. xi+1-608. Vol. 2. Part 2: Bibliography. Part 3: Errors. Part 4: Index to Introduction and Part 1. Pp. xxxiv + 609-994. (Oxford: Blackwell Scientific Publications, 1962. For Scientific Computing Services, Ltd.) $300 s$. the two volumes.

$\mathrm{T}$

HIS standard work of reference became an indispensable classic from the moment of its publication in 1946. Almost immediately, the authors set to work on a revision which is now before us. To the original three names, that of Dr. L. J. Comrie has been added; this addition will remind us that the first edition could scarcely have appeared without his unfailing support and that Part 3 of the new edition realizes a project which Comrie had long cherished and for which he had laboured inde- fatigably. It will also remind us of the courage and patience of Mrs. Betty Comrie who, since her husband's untimely death in 1950, has harnessed his Scientific Computing Service to the work of preparing this extensive revision.

Part 1 is an index according to functions, with full information about number of figures, interval and range of argument, facilities for interpolation, author and date, with some indications on availability and reliability. The 355 pages of the first edition have grown to some 600 in the new version, and even this expansion is scarcely in due proportion to the enormous output of new tables in the past twenty years, an increase due partly to new demands and partly to the fertility of modern high-speed computing machines. Part 2, the bibliography, has grown more or less in a similar ratio, and occupies the first part of volume 2. Part 3 is new; this is a 150-page list of known errors in a large number of widely used tables. Comrie had the provision of such an aid much at heart, and those who knew him personally will recall how often in the course of conversation he would speak of his intense desire to get such a list into print. There is the implicit rebuke of 27 pages devoted to one somewhat inaccurate table-maker, down to the brief commendation of careful desk-workers such as Adams and Uhler; and one may rejoice to find that even the machine may orr, though clearly very seldom.

American, German and Russian indexes are now available. A comprehensive computing library may find room for all of them, perhaps especially for the Lebedev and Fedorova 1956 book and its 1960 supplement, with its emphasis on Russian tables. If economy restricts the shelf to one index, then the choice need not be perplexing. Wide knowledge, discriminating judgment, fine scholarship, and a thorough understanding of the practical needs of the table-maker and the table-user are to be found on every page of the Fletcher, Miller, Rosenhead and Comrie work, and, into the bargain, a clean lay-out and a high level of typography.

T. A A. Broadbent

\section{STANDARD ATMOSPHERE}

\section{U.S. Standard Atmosphere, 1962}

I.C.A.O. Standard Atmosphere to 20 Kilometers; Proposed I.C.A.O. Extension to 32 Kilometers; Tables and Data to 700 Kilometers. Prepared under sponsorship of National Aeronautics and Space Administration, U.S. Air Force, U.S. Weather Bureau. Pp. xv + 278. (Washington, D.C.: Superintendent of Documents, U.S. Government Printing Office, 1962.) 3.50 dollars.

STANDARD atmosphere is always a compromise between the requirements of the diverse groups which have a hand in its preparation, and the finished product, like an anthology of verse, will not please everyone. The U.S. Standard Atmosphere, 1962, is no exception to the rule, but it will please far more people than it infuriates, because the choices made are judicious.

The tables follow the International Civil Aviation Organization's standard atmosphere at low altitudes and are close to the Committee on Space Research's international reference atmosphere (CIRA 1961) at higher altitudes $(32-700 \mathrm{~km})$. The quantities tabulated include temperature, pressure, density, number density, mean free path, molecular weight and (up to $90 \mathrm{~km}$ only) viscosity, conductivity and speed of sound. There are separate tables for metric and English units, and (up to $90 \mathrm{~km}$ ) a separate tabulation in terms of geopotential altitudo rather than geometric altitude. The interval of tabulation increases with height, from $50 \mathrm{~m}$ at sea-level to $2 \mathrm{~km}$ at $700 \mathrm{~km}$ height. The tables are preceded by an explanatory introduction. which concisely states the 